\title{
From Teacher Education to Professional Development for E-learning in an E-society
}

\author{
Raymond Morel, Jean-Claude Domenjoz, Charles Lachat and Christine Rossi \\ CPTIC (Centre Pédagogique des Technologies de l'Information et de la Communication), 2-4, \\ rue Théodore-de-Béze, PO Box 3144, CH 1211 Geneva-3, Switzerland. \\ Raymond.Morel@tecfa.unige.ch,Jean-Claude.Domenjoz@edu.ge.ch, \\ Charles.Lachat@edu.ge.ch and Christine.Rossi@edu.ge.ch
}

\begin{abstract}
This paper concerns the development of a scenario aiming at the improvement of teacher education in Geneva in the field of media, image and ICT (MITIC) in a media- and pedagogy-oriented process instead of technology-driven action as is usually the case. Among a lot of observations, experiments and constraints, the key factors we address are the lack of well-educated teachers of teachers (level F3), willingness to enhance coherence in teacher education together with pedagogical research (innovative projects), the need to take into account the evolution of the demography of teachers in professional development and the necessity to promote an attitude to and an awareness of practices in collaborative and cooperative work. In this process we have built a prototype of a new concept of teacher (F3-MITIC), and we have cooperated in a national incentive policy and proposed an agenda for the remaining problems to be solved. We conclude the presentation of our contribution by the assessment of the fundamental necessity to put in action a real e-piloting including a set of strategies, as well as projects and tools which will have to be elaborated with the actors in the field, in the four following directions: sharing data, re-defining teachers' competencies, taking care of innovative projects and designing pedagogical models of e-learning.
\end{abstract}

\section{INTRODUCTION}

\subsection{Change of paradigm: From teaching to learning}

During the last decade, changes to the role of the teacher have been widely and frequently discussed. Some particularly instructive international studies have included the CERI-OECD study (2001) suggesting six scenarios

The original version of this chapter was revised: The copyright line was incorrect. This has been corrected. The Erratum to this chapter is available at DOI: 10.1007/978-0-387-35701-0_35 
for the school of the future, and UNESCO-IFIP Curriculum (2001) which stresses the strongly interdependent multicomponent approach (teacher education is a basic component) with implementation levels (emerging, applying, integrating, transforming), not forgetting the need to preserve local implementation conditions (languages, cultures, institutions, etc.)

To go further and produce concrete proposals to promote and put them into action, we took into consideration Jacques Tardiff's (1998) ideas and also the main results of a three-year EU project named FETICHE (Formation des Enseignants aux Technologies de l'Information et de la Communication: Changements et Evolution). At the national level we elaborated a prototype of an incubator of pedagogical projects to stimulate scenarios of integrating ICT (Plan d'Actions, 2002).

\subsection{The need for coherence in teacher education}

It is very important to identify and build a grid to maintain some coherence between skills, competences and professionnal development with respect to generic objectives and more general competencies (levels F1, F2, F3).

\subsection{The bottleneck: From big announcements to reality in the field}

National policies, e-Europe, e-Learning, declarations of targets and deadlines during the last 5 years forgot the reality in the field: instead of merging or converging initial teacher education, in-service teacher education and pedagogical research, what actually happens has often been poorly linked and far removed from the 'theory'. The result in some countries is an important bottleneck characterised by a lack of well-educated teachers of teachers who have a good understanding of institutional priorities and the change of paradigm.

\subsection{The urgent need for more new teachers}

The demographic evolution of teaching staff in the next five years shows that in many countries there is a need to educate an average of $40 \%$ of new teachers. Considering that, according to the most optimistic evaluations, the number of today's teachers presently mastering ICT amounts only to $20 \%$, the huge gap stresses the urgency of bridging the chronic deficiency in educating the specialist teachers in particular. 


\section{THE F3-MITIC PROJECT AND THE TEACHER OF THE FUTURE}

According to this picture of what to do for the teacher of tomorrow, the professional development (PD) programme for teachers was oriented towards a model called F3-MITIC.

We considered it necessary to expect from all teachers of teachers, irrespective of the didactics used or of teaching level, education competences in and through media, i.e. the capability of integrating MITIC in assisting the construction of knowledge.

\subsection{F1, F2, F3 networked across the educational system}

The following codes are used in the project to define 3 different levels of education:

$\mathbf{F 1}=$ education received by students (independently of the level of education)

F2 = initial and/or continuous teacher education received by teachers (independently of the levels of education)

F3 = education received by teachers of teachers.

\subsection{Some features of F3-MITIC}

The programme is designed to focus on pedagogy, adult education, integration of ICT, collaborative learning, evaluation, basic and sustainable skills like producing document, exchanging of experiments, communicating, elaboration of scenarios, capitalising /mutualization of the production of the learners, piloting the PD through the learners i.e. the teachers of teachers, etc. The whole conception of this project is designed, as mentioned earlier, as pedagogy- rather than technology-driven. The spirit is close to Bent Andresen with his 'Design of Teacher E-Learning - the Scenario Model' (cf. IFIP WCC'2002 at Montreal August 2002).

\section{THE PROTOTYPE OF F3-MITIC IN 2001-2002}

A group of 25 existing teachers of teachers (practitioners of initial and/or in service teacher education) experimented with this model for one year (2001-2002) (Project FETICHE). The prototype F3-MITIC 2001-2002 offered very interesting observations in different directions, namely:

- implementation of the content 
- environment for collaborative work

- new methods to introduce, to experiment or to apply the prototype

- modalities for piloting, measures for accompanying the plan of action

- organisational matter,

- different modalities for evaluation

- follow-up tools

- diffusion of the information.

70 scenarios were produced throughout the 10 modules. A draft analysis in the form of a typology of all the scenarios was achieved by a fellow researcher of the Faculty of Science Education, University of Geneva (http://wwwedu.ge.ch/cptic/f3mitic/0102/scenarios/analyse_f3mitic.pdf). A web site summarizes the whole activity (http://wwwedu.ge.ch/cptic/f3mitic/ welcome.html).

\section{A BRIEF DESCRIPTION OF THE PROJECT CALLED F3-MITIC LEARNING PATH FOR PROFESSIONAL DEVELOPMENT (PD) IN TEACHER EDUCATION IN GENEVA}

F3-MITIC is a learning curve for teacher of teachers (F3) in media, image and ICT (MITIC) started by the Education Department of the Canton of Geneva.

The aim of the F3-MITIC process is to develop the motivation and competence of teaching professionals to provide courses to further teachers or to operate as resource-persons in teaching institutions.

The project is included in the general program of integrating pedagogical utilisation of MITIC in the teaching and learning processes at all education levels and is an attempt to answer the growing needs in education of teaching personnel in this field.

\subsection{Learning objectives}

The objectives of F3-MITIC are to ensure the education of teachers able to perform the specific education of teachers of teachers and of resourcepersons for pedagogical integration of media, image and ICT (information and communication technologies) (MITIC) at the initial education level (IFMES) as well as inservice education. The F3-MITIC program is designed for teachers at the three education levels: primary, secondary (compulsory and post-compulsory) and professional. 


\subsection{Contents and organisation of this learning path}

The F3-MITIC learning curve is distributed throughout the school year and brings together 25 teachers per cycle. In 2002-2003, 8 trainers from upper secondary education in Valais participated in the learning program. The program is composed of 10 modules of one to two days representing 100 course hours in class, completed by about 150 hours of distance collaborative work. Each module based on a theme provides the opportunity for the groups (two to three persons) to develop a pedagogical scenario of an innovative project using MITIC in teaching/learning and aims at developing strategies specific to adult education. From this perspective, reflexive analysis and the critique of the individual experience in each module is an integral part of this programme.

The F3-MITIC program which welcomes experienced teachers from media, image and/or ICT is not a place where new knowledge specific to each of these domains is presented but is rather a place for experimenting, exchanging practices and building up new competencies.

\subsection{Programme}

The programme is composed of the following 10 modules. It is completed in three half-days which enables the analysis of the pedagogical scenarios produced by the participants, three times a year (E-I, E-II, E-III).

\subsection{Module list}

1. Which new pedagogical competencies are required by the evolution of communication tools and practices?

2. Pedagogical and conceptual approaches to using MITIC in education.

3. Consolidation of the participants' technical and practical competences in MI, ICT (3A) and media based communication (3B).

4. Consolidation of the participants' pedagogical competencies in the areas of didactic use of fixed image or didactic use of information and communication systems.

5. Consolidation of the participants' pedagogical competences in the areas of didactic use of moving images or didactic use of modelling and simulation.

6. Didactic use of a multimedia document.

7. Realisation of a multimedia document.

8. Realisation of pedagogical Internet services.

9. Group communication using devices based on text, image and sound. 
10. Ethics and social impacts of MITIC utilisation.

\subsection{Information}

Address of website: <http://wwwedu.ge.ch/cptic/f3mitic >.

Contact Jean-Claude Domenjoz, coordinator (jean-claude.domenjoz @edu.ge.ch).

\section{TOWARDS A NATIONAL PROJECT (2002-2007)}

During the present school year (2002-2003), the model F3-MITIC is being implemented at the national level through a $100 \mathrm{MCHF}$ Project called 'PPP - ICT and Teacher Education' (5 years, 2002-2006, 2600 persons concerned ca. $2 \%$ of the teaching staff) (Communique De Presse, 2001).

The way to promote collaborative work through cantons (with different educational systems) is a key issue.

\section{AN AGENDA FOR SOLVING THE REMAINING PROBLEMS}

Such a plan obviously involves a series of problems to be considered and questions to be answered as soon as possible.

Some current issues:

- how to further reinforce the professional development phases of teacher education to encourage lifelong learning of the teaching staff ;

- for the teachers of teachers, how to implement continuing education plans to allow them to continue this evolution. How should they be certified? How to best use them after the F3-MITIC education ("rights and duties", "mixed" statutes - coexistence of statutes, working conditions, etc.)

- In the on-going generalisation the existence of a resource centre appears as a key factor to successfully complete the process. How to stimulate the establishment of such structures where they do not yet exist?

- How to stimulate the generation of innovative projects in the area of MITIC from the existing conditions in the field where partners are as numerous as spread-out, either at individual or institutional levels? (Plan d'Actions, 2002). 
- Regarding competences developed by actors of F1, F2 and F3, how to ensure coherence which would favour learning with utilisations in phase with institutional objectives and priorities?

\section{CONCLUSIONS}

At federal as well as at cantonal levels a growing attention has now been given to the needs to implement an e-piloting going beyond simple ratios not reflecting the real situation. Therefore a plan of action "e-pilotage- $\mathrm{CH}^{\prime}$ is being finalised by the Task Force "ICT et Teacher Education". The objective is to develop a series of strategies, products and tools in co-operation of actors active in the field, to allow them to better manage the integration of MITIC in teaching and learning in Switzerland thanks to the following activities:

- Data sharing

- Competence profile

- Management of innovative pedagogical projects

- Pedagogical models and e-Learning platforms.

Such a study program is certainly to be shared in the spirit of the meetings organised by IFIP (there is surely an opportunity to seize with the Focus Groups of the Working Conference).

\section{REFERENCES}

Andresen, B. (2002). TelE-LEARNING: The Challenge for the Third Millenium. Proceedings of the 17th World Computer Congress, 25-29 August, Montreal, Quebec (Eds D. Passey \& M. Kendall). Kluwer Academic Publishers.

L'École sur le Net (PPP-esn): Une Initiative de la Confédération, des Cantons et de l'Économie Privée. Retrieved from http://www.educa.ch/dyn/2992.htm

CERI-OECD (2001). Quel Avenir pour nos Écoles? Paris: OECD.

Plan d'Actions (2002). 'E-Pilotage-CH'. Task Force 'ICT et Teacher Education'. Working paper.

Project FETICHE (Formation des Enseignants aux Technologies de l'Information et de la Communication: Changements et Evolution). Retrieved from http:// www.grenoble.iufm.fr/fetiche

Tardiff, J. (Ed.) (1998). Intégrer les Nouvelles Technologies de l'Information: Quel Cadre Pédagogique? Paris: ESF.

UNESCO/IFIP (2001). Curriculum Information and Communication Technology (ICT). Retrieved from http://wwwedu.ge.ch/cptic/prospective/projets/unesco/en/welcome.html 